\title{
Impact of Haemophilus influenzae type b conjugate vaccine on bacterial meningitis in the Dominican Republic
}

\author{
Ellen H. Lee,,$^{1,2}$ Miriam Corcino, ${ }^{3}$ Arelis Moore, ${ }^{3}$ Zacarias Garib, ${ }^{3}$ \\ Chabela Peña, ${ }^{4}$ Jacqueline Sánchez, ${ }^{4}$ Josefina Fernández, ${ }^{4}$ \\ Jesús M. Feris-Iglesias, ${ }^{4}$ and Brendan Flannery ${ }^{1}$
}

Suggested citation Lee EH, Corcino M, Moore A, Garib Z, Peña C, Sánchez J, et al. Impact of Haemophilus influenzae type b conjugate vaccine on bacterial meningitis in the Dominican Republic. Rev Panam Salud Publica. 2008; 24(3):161-8.

ABSTRACT Objectives. Widespread use of Haemophilus influenzae type b (Hib) vaccines has dramatically reduced the burden of Hib disease throughout the Americas. Few studies have evaluated the impact of Hib vaccination on non-culture-confirmed disease. This study analyzed trends in probable bacterial meningitis before and after the introduction of Hib vaccine in the Dominican Republic and estimated vaccine effectiveness against Hib meningitis.

Methods. Meningitis cases among children $<5$ years of age were identified from admission records of the main pediatric hospital in Santo Domingo during 1998-2004. Laboratory criteria were used to classify meningitis cases with probable bacterial etiology; confirmed cases had positive bacterial culture or antigen detection in cerebrospinal fluid. Cumulative incidence rates of confirmed and probable bacterial meningitis were calculated for children living in the National District. Confirmed cases of Hib meningitis were enrolled in a case-control study with age- and neighborhood-matched control children to calculate vaccine effectiveness. Results. Before vaccine introduction, annual rates of meningitis with probable bacterial etiology were 49 cases per 100000 children < 5 years old; Hib accounted for $60 \%$ of confirmed bacterial cases. During 2002-2004, after vaccine introduction, annual rates of probable bacterial meningitis were $65 \%$ lower at 16 cases per 100 000, and Hib accounted for $26 \%$ of confirmed cases. Rates of Hib meningitis and probable bacterial meningitis with no determined etiology declined by 13 and 17 cases per 100 000, respectively.

Conclusions. Introduction of Hib vaccine substantially reduced the incidence of confirmed and probable bacterial meningitis in the Dominican Republic. The estimated impact of Hib vaccination was twice as great when non-culture-confirmed disease was included.

Key words Haemophilus influenzae type b conjugate vaccine, bacterial meningitis, immunization, Dominican Republic.

Division of Bacterial Diseases, National Center for Immunizations and Respiratory Diseases and

2 Epidemic Intelligence Service, Career Development Division, Office of Workforce and Career Development, Centers for Disease Control and Prevention, Atlanta, Georgia, USA. Send correspondence to:
Ellen Lee, 238 Clinton Street, Unit F, Brooklyn, New York 11201, USA; phone (404) 323-3815; fax (212) 262-9461; e-mail: ellelee@hotmail.com.

3 Programa Ampliado de Inmunización, Secretaría de Estado de Salud Pública y Asistencia Social, Santo Domingo, Dominican Republic.
4 Departamento de Enfermedades Infecciosas, Clínica Infantil Dr. Robert Reid Cabral, Santo Domingo, Dominican Republic. 
Haemophilus influenzae type $\mathrm{b}$ (Hib) conjugate vaccines are included in routine childhood immunizations in all countries in Latin America and the Caribbean except Haiti (1). Hib was a leading bacterial cause of meningitis in Latin American children before the introduction of conjugate vaccines $(2,3)$, which led to dramatic reductions in the number of cases of Hib meningitis (4-6). However, confirmed cases of Hib meningitis represent only a fraction of all Hib disease. Analysis of laboratory data from hospitals in Argentina, South Africa, and Rwanda showed significant reductions in suspected bacterial meningitis cases of undetermined etiology after Hib vaccine was introduced in these countries, suggesting the potential to use surrogate markers of bacterial meningitis to measure the impact of $\mathrm{Hib}$ vaccine $(7,8)$.

Difficulties in isolating Hib often result in underappreciation of the disease burden and potential benefits of vaccination. In developing countries like the Dominican Republic, the introduction of Hib vaccine was delayed because of the relatively high cost of conjugate vaccines and the lack of data on disease burden. Demonstration of the impact of the introduction of Hib vaccine on reductions in disease burden is important for the sustainability of the vaccination program. Evaluations of vaccine impact and costeffectiveness analyses should include effects on non-culture-confirmed disease endpoints to provide a truer picture of vaccine benefits (9).

The objective of this study was to evaluate the impact of routine childhood immunization against $\mathrm{Hib}$ on both confirmed and probable cases of bacterial meningitis in the Dominican Republic, where bacterial meningitis has been a reportable disease since 1998 (10). Before the introduction of Hib conjugate vaccines into the routine infant immunization schedule in 2001, $\mathrm{Hib}$ was the leading cause of bacterial meningitis in children after the first month of life (11). This report summarizes trends in confirmed and probable cases of bacterial meningitis among children admitted to the main pediatric referral hospital in Santo Do- mingo from 1998 through 2004 and presents the results of a case-control study of the effectiveness of Hib vaccine against culture-confirmed disease.

\section{MATERIALS AND METHODS}

\section{Study population}

The Dominican Republic is a developing country in the Caribbean region with a population of 9.6 million. Its child mortality rate of 35 deaths per 1000 live births ranks second highest behind Haiti among Caribbean nations and ninth among the 35 countries in the Americas region $(12,13)$. The Dominican Republic, with a per capita gross national income of more than US \$2 000, is not among the 72 poorest countries eligible to receive support for immunizations through the Global Alliance for Vaccines and Immunization (14). The national government funds approximately $60 \%$ of routine immunizations in the Dominican Republic (12), with the balance provided by international donors. From 2001 through 2005, Hib conjugate vaccine for routine childhood immunization was provided by a grant from the Japan International Cooperation Agency (15).

In July and August 2001, before Hib conjugate vaccine was introduced into the routine immunization schedule, a national campaign was conducted to vaccinate all children 2 to 35 months of age with a single dose of Hib conjugate vaccine (PRP-CRM ${ }_{197}$, mutant diphtheria toxin conjugate, HibTITER $^{\text {TM }}$, Lederle Praxis, Pearl River, United States of America). Vaccination data suggested that about $76 \%$ of the target population was vaccinated. Beginning in December 2001, Hib conjugate vaccine (PRP-T, tetanus toxoid conjugate, Hiberix ${ }^{\mathrm{TM}}$, Glaxo SmithKline, Rixensart, Belgium) was introduced into the routine immunization schedule as part of a pentavalent combination with diphtheria, whole cell pertussis, tetanus, and hepatitis B vaccines (Tritanrix ${ }^{\circledR}$, GlaxoSmithKline), with doses recommended at 2, 4, and 6 months of age. According to official estimates, national coverage with three doses of $\mathrm{Hib}$ vaccine ranged from $75 \%$ to $83 \%$ during 2002-2004; World Health Organization-United Nations Children's Fund (WHOUNICEF) estimates for the same period ranged from $65 \%$ to $83 \%$ (12).

\section{Surveillance for bacterial meningitis}

The National District-including the capital, Santo Domingo, and the surrounding periurban area-accounts for approximately $40 \%$ of the country's population, with 300000 children less than 5 years of age. In 1998 and 1999, active, population-based surveillance for bacterial meningitis in eight hospitals (four public and four private) in the National District documented an incidence of 13 cases of $\mathrm{Hib}$ meningitis per 100000 children less than 5 years of age (11). During this 2-year period, surveillance officers regularly reviewed laboratory records and admission logs to identify case patients and completed standardized case report forms. From 2000 through 2004, surveillance for pediatric meningitis cases was passive.

During the active surveillance period, Clínica Infantil Dr. Robert Reid Cabral (CIRRC), the main pediatric referral hospital in the country, accounted for approximately $80 \%$ of all confirmed and probable cases of bacterial meningitis identified. Between 1998 and 2004, clinical criteria for hospitalizing children with suspected meningitis and for performing lumbar puncture, as well as routine laboratory testing for etiologic agents, did not change at CIRRC. In 2004, we retrospectively reviewed all admissions and laboratory records for children hospitalized at CIRRC with bacterial meningitis.

\section{Case definitions}

Probable bacterial meningitis was defined as a child hospitalized with suspected meningitis from whom the cerebrospinal fluid (CSF) was either visibly turbid or met two of the fol- 
lowing criteria: glucose $<40 \mathrm{mg} / \mathrm{dL}$, protein $>45 \mathrm{mg} / \mathrm{dL}, \geq 100$ leukocytes/ $\mathrm{mm}^{3}$, or $>80 \%$ polymorphonuclear cells. Confirmed bacterial meningitis was defined as a child hospitalized with suspected meningitis with positive bacterial culture or antigen detection by latex agglutination in CSF. $H$. influenzae isolates were serotyped by latex agglutination. For trend analyses, probable case counts include all confirmed cases that met criteria for probable bacterial meningitis. Case patients residing outside the National District at the time of illness were excluded.

\section{Case-control study}

We conducted a retrospective casecontrol study in October 2004 to investigate undervaccination as a factor contributing to ongoing transmission of Hib after introduction of the conjugate vaccine. Children hospitalized during the study period (26 August 2001 to 26 October 2004) with confirmed Hib meningitis were enrolled as cases. Case patients had to be at least 60 days old and reside in the $\mathrm{Na}$ tional District at the time of illness. Cases occurring within 2 weeks of the national Hib vaccination campaign in July and August 2001 were excluded. $\mathrm{Hib}$ vaccine doses were considered valid if administered at least 15 days before illness. For both cases and controls, children had to be born on or after 13 August 1998 and therefore eligible to receive at least one dose of $\mathrm{Hib}$ vaccine, either during the national campaign or as part of the routine immunization series.

Control children were identified by door-to-door visits in the neighborhood where a case patient lived at the time of the study. Briefly, trained interviewers randomly chose a starting direction from the case patient's house; at the fourth house, they asked whether there was a child born within a specified interval of the case patient's birth date and continued inquiring at every subsequent house until three eligible control children were identified. Control children with a his- tory of meningitis were excluded. Control children had to have been at least 60 days old at the time of the case patient's illness, and they had to have been residing in the National District for at least 1 month before the case patient's hospitalization. We used the following criteria to match by age: birth dates of matched controls had to be within 60 days of the case patient's birth date if illness occurred within the first year of life or within 180 days if illness occurred between ages 1 and 4 years. Only one child in a household was included.

For each case and control child, trained interviewers administered a questionnaire to the caregiver about individual and household characteristics (e.g., breastfeeding history, daycare attendance, previous hospitalizations, parental education, household crowding, housing conditions) and vaccination history. Dates of vaccination were recorded from the child's health card, certificates from vaccination campaigns, or vaccination and medical records at the health centers where vaccinations were received. In the absence of a documented vaccination history, interviewers solicited information about the route and site of administration for each vaccination reported by the caregiver. For case patients, vaccination history solicited at the time of hospital admission was used in the absence of other documents indicating vaccination status.

For the primary analysis estimating the effectiveness of two or more doses of Hib conjugate vaccine compared with no vaccine, we assumed $90 \%$ effectiveness for two or more doses, with $50 \%$ to $60 \%$ coverage for controls receiving two or more doses of $\mathrm{Hib}$ vaccine. With these parameters, the sample size required $12-16$ cases and 36-48 controls, with sufficient precision to exclude a lower confidence bound of $<30 \%$, approximately equal to a power of $80 \%$. For the secondary analysis calculating the effectiveness of one or more doses of Hib conjugate vaccine compared with no vaccine, we assumed $70 \%$ effectiveness for one or more doses of Hib vaccine and estimated that $70 \%$ of controls had re- ceived at least one dose of Hib vaccine. For the secondary analysis, the sample size required 33 cases and 99 controls.

\section{Analysis}

We calculated cumulative incidence rates by dividing the number of cases hospitalized each calendar year among children ages 2 to 59 months resident in the National District by the under-5 population of the district for 2002, estimated by a census conducted that year. We calculated relative risk (RR) and 95\% confidence intervals (CIs) comparing average rates of confirmed and probable bacterial meningitis in 1998 and 1999, during active surveillance, or in 2000 and 2001, during passive surveillance, with rates for 2002 through 2004, after the introduction of Hib conjugate vaccine. As changes in surveillance may have contributed to fewer cases of bacterial meningitis identified after 1999, we compared the odds of identifying Hib as a cause of probable bacterial meningitis (number of CSF specimens positive for $\mathrm{Hib} /$ number of specimens negative for $\mathrm{Hib}$ ) in 2000-2001 and 2002-2004 with the prevaccine period, according to the method of Cowgill et al. (16). To examine short-term effects of the national Hib vaccination campaign on disease incidence, we also compared rates of $\mathrm{Hib}$ meningitis in the National District during the 4 months after the campaign with rates during the same 4 months in the preceding 3 years (1998-2000).

For the case-control study, we calculated matched odds ratios (ORs) for dichotomous variables and used Wilcoxon's rank sum test for continuous variables. To compare vaccination status, we calculated ORs and exact 95\% CIs by using conditional logistic regression. Vaccine effectiveness was estimated as (1 - OR) $\times 100 \%$ (17). Unvaccinated children were the reference group. Receipt of two or three doses of Hib conjugate vaccine was combined in the final analysis. Because vaccination status could not be determined for several control children, we conducted a sensitivity analysis assuming that all 
TABLE 1. Meningitis cases among children $<5$ years of age meeting criteria for probable bacterial meningitis or confirmed bacterial meningitis, Clínica Infantil Robert Reid Cabral, Dominican Republic, 1998-2004

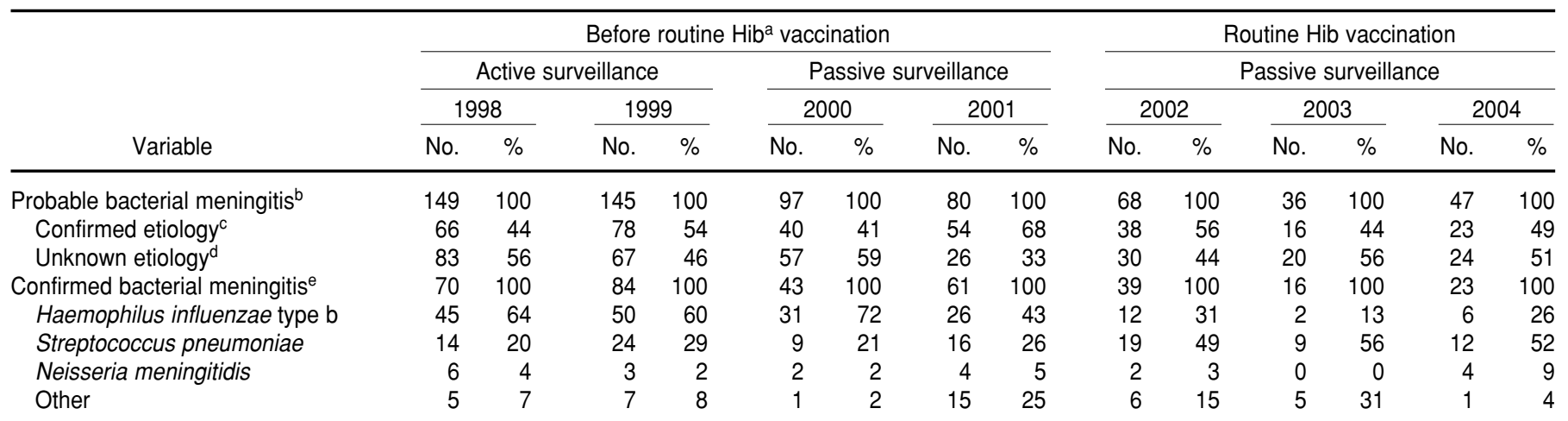

a Hib: Haemophilus influenzae type b.

${ }^{b}$ Defined as clinically diagnosed meningitis with either turbid cerebrospinal fluid (CSF) or two or more of the following: glucose $<40 \mathrm{mg} / \mathrm{dL}, \mathrm{protein}>45 \mathrm{mg} / \mathrm{dL}, \geq 100$ leukocytes/mm ${ }^{3},>80 \%$ polymorphonuclear cells.

c Defined as clinically diagnosed meningitis with either isolation of bacterial agent from CSF or positive latex agglutination test for bacterial antigen in CSF.

d Unknown etiology includes 180 cases with negative culture and latex agglutination results; 84 cases negative by culture, not tested for latex agglutination; 36 cases for which neither culture nor latex agglutination was performed; and 6 cases for which results were not known.

e Includes nine cases of meningitis due to Hib, three due to $S$. pneumoniae, two due to $N$. meningitidis, and seven due to other organisms that did not meet laboratory criteria for probable bacterial meningitis; seven Hib cases, three $S$. pneumoniae cases, and one N. meningitidis case were positive by latex agglutination only.

control children with unknown vaccination status were not vaccinated. Analyses were conducted in EpiInfo version 6.04 (Centers for Disease Control and Prevention, Atlanta, Georgia) and SAS 9.1 (SAS Institute Inc., Cary, North Carolina).

\section{RESULTS}

\section{Surveillance}

From 1998 through 2004, there were 622 cases of meningitis among children younger than 5 years of age who met criteria for probable bacterial meningitis. In all, there were 336 confirmed cases of bacterial meningitis during the period; $21(6 \%)$ confirmed cases did not fulfill laboratory criteria for probable bacterial meningitis. Hib accounted for 172 of 336 (51\%) confirmed cases (Table 1); 163 (95\%) were confirmed by culture and $113(66 \%)$ were positive by latex agglutination in CSF. In 1998 and 1999, before widespread use of conjugate vaccine, Hib was the leading cause of bacterial meningitis in children, accounting for $62 \%$ of confirmed cases and $31 \%$ of probable cases. From 2002 through 2004, Hib accounted for $26 \%$ of confirmed cases and $13 \%$ of probable cases of bacterial meningitis in children. There were 44 fatal cases of probable bacterial meningitis during the surveillance period; of the $8(18 \%)$ fatal cases due to Hib, 1 occurred after the introduction of Hib conjugate vaccine.

Between 1998 and 2004, the annual cumulative incidence of probable bacterial meningitis decreased from 49 to 16 cases per 100000 children in the National District (Figure 1), a reduction of 33 cases per 100 000. Compared with the average incidence in 1998 and 1999, rates of probable bacterial meningitis in 2002 through 2004, after the introduction of Hib conjugate vaccine, were $65 \%$ lower (RR, 0.35; $95 \%$ $\mathrm{CI}, 0.25$ to 0.48 ). Incidence of confirmed Hib meningitis decreased $84 \%$ from 15 to 2 cases per 100000 (rate difference, 13 cases per 100 000; RR, 0.16; $95 \% \mathrm{CI}, 0.07$ to 0.34 ). In addition, rates of probable bacterial meningitis with no determined etiology decreased $67 \%$, from 25 to 8 cases per 100000 (rate difference, 17 cases per 100000 ; RR, $0.33 ; 95 \%$ CI, 0.21 to 0.52 ). For 2002 through 2004, the incidence of confirmed Streptococcus pneumoniae meningitis was not significantly different from the prevaccine average (RR, 0.72; $95 \%$ CI, 0.35 to 1.47 ).

The number of cases of probable bacterial meningitis and confirmed
Hib and S. pneumoniae meningitis were lower in 2000 than in 1998 and 1999. However, the odds of identifying Hib from cases of probable bacterial meningitis did not change during 20002001 compared with the baseline 19981999, suggesting that this decline was not due to Hib vaccination (Table 2). For the period 2002-2004, the odds of identifying Hib from cases of probable bacterial meningitis were significantly lower than during the prevaccine period. When we compared the incidence of Hib meningitis during the 4 months after the national Hib vaccination campaign in 2001 with the same 4-month period in 1998-2000, we observed no significant decline in incidence of Hib meningitis (data not shown).

\section{Case-control study}

We enrolled 32 of 41 (78\%) eligible children who had been hospitalized with Hib meningitis after the national Hib vaccination campaign in 2001; the remaining 9 children could not be located. Ten (31\%) of the case patients had received Hib conjugate vaccine, including one who had received two doses of vaccine before illness (Table 3). No case patient received three doses of $\mathrm{Hib}$ con- 
FIGURE 1. Incidence of meningitis meeting criteria for probable bacterial etiology: Haemophilus influenzae type $\mathrm{b}(\mathrm{Hib})$ meningitis and Streptococcus pneumoniae meningitis among children < 5 years of age, National District, Dominican Republic, 1998-2004



jugate vaccine before illness. From the neighborhoods where case patients resided at the time of illness, we identified 96 age-matched controls. Among 87 control children for whom any report of vaccination history could be obtained, $50(57 \%)$ had received at least one dose and $23(26 \%)$ had received at least two doses of Hib conjugate vaccine before the case patient's illness (Table 3). Control children were similar to case patients with respect to sex, history of breastfeeding, daycare attendance, exposure to household smoke, parental education, and possession of certain household items (data not shown). At the time of the study, households of control children had fewer inhabitants (median, 5 people; range, 2-11) than households of case patients (median, 6 people; range, 3-11; $P<0.05)$.

Using documented and verbal reports of vaccination history, receipt of at least two doses of Hib conjugate vaccine was $94 \%$ effective (95\% CI, $60 \%$ to $100 \%$ ) against confirmed Hib meningitis (Table 3). When analyses were limited to the 32 case patients and 71 matched control children with documented vaccination histories, two or more doses were $92 \%$ effective $(95 \% \mathrm{CI}$, $37 \%$ to $100 \%$ ). In the sensitivity analysis,
TABLE 2. Cases of probable bacterial meningitis among children $<5$ years of age admitted to Clínica Infantil Robert Reid Cabral, Dominican Republic, according to result of Haemophilus influenzae type $b$ (Hib) laboratory tests and odds of positive Hib result

\begin{tabular}{|c|c|c|c|c|}
\hline \multirow[b]{2}{*}{ Year } & \multicolumn{2}{|c|}{ Hib culture or latex result } & \multirow[b]{2}{*}{ Odds of positive Hib result } & \multirow[b]{2}{*}{ OR $(95 \% \mathrm{Cl})^{\mathrm{b}}$} \\
\hline & Positive & Negative $^{a}$ & & \\
\hline 1998-1999 & 90 & 166 & 0.54 & Referent \\
\hline 2000-2001 & 53 & 121 & 0.44 & $0.81(0.52-1.24)$ \\
\hline 2002-2004 & 20 & 130 & 0.15 & $0.28(0.16-0.50)^{\mathrm{c}}$ \\
\hline
\end{tabular}

a Excludes probable bacterial meningitis cases with no latex and no culture results.

${ }^{b}$ Odds ratios and exact $95 \%$ confidence intervals.

c $P<0.001$.

TABLE 3. Doses of Haemophilus influenzae type $b$ (Hib) vaccine received by children with confirmed Hib meningitis and age-matched neighborhood control children, with estimates of vaccine effectiveness

\begin{tabular}{lcccc}
\hline $\begin{array}{l}\text { Number of Hib } \\
\text { vaccine doses } \\
\text { received }^{\text {a }}\end{array}$ & $\begin{array}{c}\text { No. of } \\
\text { cases (\%) }\end{array}$ & $\begin{array}{c}\text { No. of } \\
\text { controls (\%) }\end{array}$ & OR $(95 \% \text { Cl) })^{\mathrm{b}}$ & $\begin{array}{r}\% \text { effectiveness } \\
(95 \% \text { Cl) }\end{array}$ \\
\cline { 2 - 5 } & $n=32$ & $n=87$ & Referent & NA $^{\mathrm{c}}$ \\
0 & $22(69)$ & $37(43)$ & $0.48(0.12,1.63)$ & $52(-63$ to 88) \\
1 & $9(28)$ & $27(31)$ & $0.13(0,0.86)$ & $87(14$ to 100) \\
2 & $1(3)$ & $13(15)$ & $0.10(0,0.67)$ & $90(33$ to 100) \\
3 & 0 & $10(11)$ & $0.06(0,0.40)$ & $94(60$ to 100)
\end{tabular}

a Excludes 9 control children with unknown vaccination history. Sources of vaccine history included child health record or hospital chart, supplementary vaccine cards distributed during immunization campaigns, and logbooks at vaccination posts; includes vaccine doses reported by parents of 3 case patients and 16 control children with no documented record.

b Odds ratios and exact $95 \%$ confidence intervals were calculated using conditional logistic regression. Vaccine effectiveness is defined as $1-O R$.

c NA, not applicable.

${ }^{d}$ Includes all children who reported receiving two or three doses. 
assuming all nine control children with unknown vaccine history had not received Hib vaccine, two or more doses were $93 \%$ effective $(95 \% \mathrm{CI}, 55 \%$ to $100 \%)$. Including potential confounding variables in bivariate models did not change the effectiveness estimates for receipt of at least two doses of Hib conjugate vaccine (data not shown).

\section{DISCUSSION}

Introduction of $\mathrm{Hib}$ conjugate vaccine into routine childhood immunizations significantly reduced the incidence of Hib meningitis among children in the National District in the Dominican Republic. In addition, Hib vaccination was most likely responsible for significant reductions observed in the incidence of probable bacterial meningitis of undetermined etiology, while the incidence of pneumococcal meningitis did not change. Our analyses suggest that the vaccinepreventable burden of Hib disease was greater than had been estimated previously (11), as has been demonstrated in randomized trials of Hib conjugate vaccines in developing countries (18).

Receipt of at least two doses of Hib vaccine was highly effective in preventing meningitis among young children, but the effectiveness of one dose was not significant. The study was not able to determine the effectiveness of the national campaign to administer a single dose of Hib vaccine to all children $<3$ years old before Hib conjugate was added to the routine childhood series. The estimated effectiveness of the Hib component of the pentavalent combination vaccine in the routine immunization program was similar to that of Hib-tetanus toxoid conjugate vaccine in Chile (19), Uganda (20), and The Gambia (21) as well as to that of other Hib conjugate vaccines (22).

Among the children enrolled as controls in the case-control study, vaccine coverage was lower than Ministry of Health estimates. Lower coverage may be due in part to vaccine availability, as pentavalent vaccine was not available in all health posts throughout the National District until mid-2002.
Among control children born after June 2002, 15 (68\%) of 22 had received one or more doses of Hib-containing vaccine, approximately equivalent to national estimates of Hib vaccine coverage. The case-control investigation suggested that undervaccination of eligible children contributed to ongoing Hib disease transmission after introduction of the vaccine.

This study demonstrates the value of prevaccine surveillance for meningitis that includes surrogate indicators of bacterial meningitis using standard laboratory definitions $(7,8)$. Reductions in rates of probable bacterial meningitis of unknown etiology were comparable to declines in confirmed Hib meningitis, suggesting that the vaccine-preventable burden of $\mathrm{Hib}$ disease was higher than that confirmed by culture and antigen detection alone. Interestingly, no reduction in culture-negative purulent meningitis cases was noted after the introduction of Hib vaccine in Malawi, where nearly $80 \%$ of cases of purulent meningitis were confirmed by culture (23). In the Dominican Republic, a substantial proportion of $\mathrm{Hib}$ meningitis cases may have been missed because of antibiotic use before admission, insensitivity of diagnostic methods, or specimens that could not be tested.

In addition to acute morbidity and mortality, Hib meningitis is associated with neurologic sequelae such as hearing loss and cognitive delay (24). This retrospective review of hospital and laboratory records was unable to evaluate the impact of $\mathrm{Hib}$ vaccination on the proportion of Hib meningitis survivors who had neurologic sequelae before and after introduction of the vaccine. Among etiologies of bacterial meningitis, Hib was responsible for most cases among children who received auditory testing at CIRRC between 1993 and 2001, with more than $50 \%$ of those tested having documented hearing loss. ${ }^{5}$ Reduction in

\footnotetext{
5 Feris JM, Fernández J, Terrera C, Peña C, Sánchez J, Polanco D, et al. Factors associated with hearing loss in Dominican children with bacterial meningitis [poster presentation]. At: 3rd World Congress of Pediatric Infectious Diseases, Santiago de Chile, 19-23 November 2002.
}

long-term disability is an important benefit of Hib vaccine introduction and should be included in cost-effectiveness analyses. The current evaluation focused on meningitis, a small proportion of the burden of Hib disease in developing countries. Pneumonia, which makes up a larger proportion of the global Hib disease burden, was not included in the prevaccine surveillance system, and the case-control study focused only on confirmed cases of Hib meningitis. In two case-control studies conducted in Latin America, Hib vaccination was $30 \%$ to $50 \%$ effective against severe, $\mathrm{x}$-ray-confirmed pneumonia among young children $(25,26)$.

This study has several limitations. First, use of the Hib conjugate vaccine before national immunization was not well documented. In 1997, a donation of Hib vaccine was used in a limited campaign to administer a single dose of vaccine to children 12 to 23 months of age; reported coverage was $56 \%$ of the target population (Expanded Program on Immunization, Dominican Republic, unpublished data). In addition, some children in the National District may have received Hib vaccine in the private sector before it was introduced nationwide. A second limitation is the use of only one hospital for our longitudinal study of meningitis surveillance data and for case identification for the case-control study. Methods of case identification and record keeping were not maintained consistently at other hospitals within the $\mathrm{Na}$ tional District after the active surveillance period in 1998-1999. At CIRRC, the largest number of cases of probable bacterial meningitis was observed during the active surveillance period, and changes in record-keeping practices after this period may account for apparent declines in cases of bacterial meningitis in 2000, before widespread use of the $\mathrm{Hib}$ vaccine. Although CIRRC is the major pediatric referral hospital in the Dominican Republic, the findings from our analysis of surveillance data and the case-control study may not be representative of the population at large. Finally, the casecontrol study of vaccine effectiveness had limited power to consider poten- 
tial confounding factors, including the presence of underlying illness among cases. Estimates of vaccine effectiveness remained high if we assumed that control children with unknown vaccine histories were not vaccinated.

Countries in Latin America were among the first developing countries to introduce Hib conjugate vaccines in routine immunization programs $(4,6)$, beginning with Uruguay in 1994. Despite early documented success, these vaccines had not been introduced in the poorer countries in the region before 2000 because of the high cost of the vaccines. In 2006, the government of the Dominican Republic began purchasing pentavalent vaccine containing Hib conjugate through the Pan
American Health Organization's Revolving Fund, which purchases vaccines in bulk for countries in the region to obtain lower prices. This decision required authorization from the National Senate to increase the budget allocation from 30 to 268 million pesos per year (approximately U.S. $\$ 8$ million), an increase of $88 \%$ (Expanded Program on Immunization, Dominican Republic, unpublished data). Demonstration of reduced disease burden after the introduction of Hib conjugate vaccine was important to justify the increase in spending on immunization. When governments are faced with the decision to increase immunization budgets to sustain vaccination programs, demonstration of vaccine impact and effectiveness is critical to the decisionmaking process.

Acknowledgments. This study was supported by the Japan International Cooperation Agency, UNICEF, and the United States Agency for International Development. The authors are grateful for the assistance of Elizabeth Gómez, Maria Cristina Pedreira, Anne Schuchat, Elizabeth Zell, and the team of interviewers (Juan de Leon, Patricia Grullon, Angelica Henriquez, Danilo Mariano, Beatriz Martinez, Clara Molina, Esperanza Rufino, Rafael Severino, Francisco Torres) in the Dominican Republic.

\section{REFERENCES}

1. Danovaro-Holliday MC, Garcia S, de Quadros C, Tambini G, Andrus JK. Progress in vaccination against Haemophilus influenzae type $\mathrm{b}$ in the Americas. PLoS Medicine. 2008;5(4):530-6.

2. Peltola H. Haemophilus influenzae type $\mathrm{b}$ disease and vaccination in Latin America and the Caribbean. Pediatr Infect Dis J. 1997;16(8): 780-7.

3. Bennett J, Platonov A, Slack M, Mala P, Burton A, Robertson S. Haemophilus influenzae type $b$ (Hib) meningitis in the pre-vaccine era: a global review of incidence, age distributions, and case-fatality rates. Geneva: WHO; 2002.

4. Landaverde M, Di Fabio JL, Ruocco G, Leal I, de Quadros C. Introducción de la vacuna conjugada contra Hib en Chile y Uruguay. Rev Panam Salud Publica. 1999;5(3):200-6.

5. Ribeiro GS, Reis JN, Cordeiro SM, Lima JB, Gouveia EL, Petersen M, et al. Prevention of Haemophilus influenzae type $\mathrm{b}$ (Hib) meningitis and emergence of serotype replacement with type a strains after introduction of Hib immunization in Brazil. J Infect Dis. 2003;187(1): 109-16.

6. Wenger JD, Di Fabio J, Landaverde JM, Levine OS, Gaafar T. Introduction of Hib conjugate vaccines in the non-industrialized world: experience in four 'newly adopting' countries. Vaccine. 1999;18(7-8):736-42.

7. Martin M, Casellas JM, Madhi SA, Urquhart TJ, Delport SD, Ferrero F, et al. Impact of Haemophilus influenzae type $\mathrm{b}$ conjugate vaccine in South Africa and Argentina. Pediatr Infect Dis J. 2004;23(9):842-7.

8. Muganga N, Uwimana J, Fidele N, Gahimbare L, Gessner BD, Mueller JE, et al. Haemophilus influenzae type $\mathrm{b}$ conjugate vaccine impact against purulent meningitis in Rwanda. Vaccine. 2007;25(39-40):7001-5.
9. Alvis Guzman N, de la Hoz Restrepo F, Vivas Consuelo D. Relación costo-efectividad de la vacuna contra Haemophilus influenzae tipo b en niños menores de dos años de edad en Colombia. Rev Panam Salud Publica. 2006;20(4): 248-55.

10. Secretaria de Estado de Salud Publica y Asistencia Social RD. Normas nacionales para la vigilancia epidemiológica de enfermedades transmisibles y otros eventos. In: Secretaria de Estado de Salud Publica y Asistencia Social SD, Distrito Nacional, editor; 1998.

11. Gomez E, Peguero M, Sanchez J, Castellanos PL, Feris J, Pena C, et al. Population-based surveillance for bacterial meningitis in the Dominican Republic: implications for control by vaccination. Epidemiol Infect. 2000;125(3): 549-54

12. World Health Organization. Immunization profile-Dominican Republic. Geneva: WHO. Available from: http://www.who.int/ vaccines/globalsummary/immunization/ countryprofileresult.cfm. Accessed 29 March 2008.

13. WHO Statistical Information System Core Health Indicators. Geneva: WHO. Available from: http://www.who.int/whosis/ database/core/core_select.cfm. Accessed 29 March 2008.

14. GAVI Alliance. Eligible countries. Geneva: GAVI Alliance. Available from: http://www. gavialliance.org/support/who/eligible/ index.php. Accessed 29 March 2008.

15. Japan International Cooperation Agency. Latin America: List of JICA projects in Central America. Tokyo: JICA. Available from: http://www.jica.go.jp/usa/activities/list. html. Accessed 29 March 2008.

16. Cowgill KD, Ndiritu M, Nyiro J, Slack MP, Chiphatsi S, Ismail A, et al. Effectiveness of
Haemophilus influenzae type $\mathrm{b}$ conjugate vaccine introduction into routine childhood immunization in Kenya. JAMA. 2006;296(6): 671-8.

17. Orenstein WA, Bernier RH, Dondero TJ, Hinman AR, Marks JS, Bart KJ, et al. Field evaluation of vaccine efficacy. Bull World Health Organ. 1985;63(6):1055-68.

18. Andrade AL, Martelli CM. Globalisation of Hib vaccination-how far are we? Lancet. 2005;365(9453):5-7.

19. Lagos R, Horwitz I, Toro J, San Martin O, Abrego P, Bustamante C, et al. Large scale, postlicensure, selective vaccination of Chilean infants with PRP-T conjugate vaccine: practicality and effectiveness in preventing invasive Haemophilus influenzae type $\mathrm{b}$ infections. Pediatr Infect Dis J. 1996;15(3):216-22.

20. Lee EH, Lewis RF, Makumbi I, Kekitiinwa A, Ediamu TD, Bazibu M, et al. Haemophilus influenzae type $\mathrm{b}$ conjugate vaccine is highly effective in the Ugandan routine immunization program: a case-control study. Trop Med Int Health. 2008;13(4):495-502.

21. Adegbola RA, Secka O, Lahai G, Lloyd-Evans $N$, Niie A, Usen $S$, et al. Elimination of Haemophilus influenzae type $\mathrm{b}$ (Hib) disease from The Gambia after the introduction of routine immunisation with a Hib conjugate vaccine: a prospective study. Lancet. 2005; 366(9480):144-50.

22. Obonyo CO, Lau J. Efficacy of Haemophilus influenzae type $b$ vaccination of children: a metaanalysis. Eur J Clin Microbiol Infect Dis. 2006; 25(2):90-7.

23. Daza P, Banda R, Misoya K, Katsulukuta A, Gessner BD, Katsande R, et al. The impact of routine infant immunization with Haemophilus influenzae type $\mathrm{b}$ conjugate vaccine in Malawi, a country with high human immu- 
nodeficiency virus prevalence. Vaccine. 2006; 24(37-39):6232-9.

24. Grimwood K, Anderson P, Anderson V, Tan L, Nolan T. Twelve year outcomes following bacterial meningitis: further evidence for persisting effects. Arch Dis Child. 2000;83(2):111-6.

25. Andrade AL, de Andrade JG, Martelli CM, e Silva SA, de Oliveira RM, Costa MS, et al. Ef- fectiveness of Haemophilus influenzae $\mathrm{b}$ conjugate vaccine on childhood pneumonia: a casecontrol study in Brazil. Int J Epidemiol. 2004; 33(1):173-81.

26. de la Hoz F, Higuera AB, Di Fabio JL, Luna M, Naranjo AG, de la Luz Valencia M, et al. Effectiveness of Haemophilus influenzae type $\mathrm{b}$ vaccination against bacterial pneumonia in Colombia. Vaccine. 2004;23(1):36-42.

Manuscript received on 7 March 2007. Revised version accepted for publication on 25 April 2008.
RESUMEN

Impacto de la vacuna conjugada contra Haemophilus influenzae tipo $b$ sobre la meningitis bacteriana en la República Dominicana

Palabras clave
Objetivos. El uso generalizado de la vacuna contra Haemophilus influenzae tipo b (Hib) ha permitido reducir radicalmente la carga de enfermedad por Hib en las Américas. Pocos estudios han evaluado el impacto de la vacunación contra Hib sobre los casos no confirmados mediante cultivo. En este estudio se analizaron las tendencias en el número de casos probables de meningitis bacteriana antes y después de la introducción de la vacuna contra Hib en la República Dominicana y se estimó la eficacia de la vacuna contra la meningitis.

Métodos. Se identificaron los casos de meningitis en niños menores de 5 años a partir de los registros de ingreso del principal hospital pediátrico de Santo Domingo entre 1998 y 2004. Los casos de meningitis con probable etiología bacteriana se clasificaron según criterios de laboratorio; los casos confirmados contaban con cultivo bacteriano positivo o detección de antígenos específicos en el líquido cefalorraquídeo. Se calcularon las tasas de incidencia acumulada de casos confirmados y probables de meningitis en los niños que vivían en el Distrito Nacional. Los casos confirmados de meningitis por Hib se incorporaron a un estudio de casos y controles - pareados según la edad y el barrio de residencia- para calcular la eficacia de la vacuna.

Resultados. Antes de la introducción de la vacuna, la tasa anual de meningitis de posible etiología bacteriana era de 49 casos por 100000 niños menores de 5 años; de los casos confirmados de origen bacteriano, $60 \%$ fue por Hib. En el período 2002-2004, después de la introducción de la vacuna, la tasa anual de meningitis de posible etiología bacteriana fue de 16 casos por 100 000, es decir 65\% más baja, y $26 \%$ de los casos confirmados correspondieron a Hib. Las tasas de meningitis por Hib y de posible origen bacteriano de etiología desconocida se redujeron en 13 y 17 casos por 100000 , respectivamente.

Conclusiones. La introducción de la vacuna contra Hib redujo sustancialmente la incidencia de casos de meningitis confirmados y probables en la República Dominicana. El impacto estimado de la vacunación contra Hib fue dos veces mayor cuando se consideraron los casos no confirmados mediante cultivo.

Haemophilus influenzae type b, vacunas contra Haemophilus, meningitis bacteriana, inmunización, República Dominicana. 